Article

\title{
Environmental Education for Students from School to University: Case Study on Biorefineries
}

\author{
Sergio Nogales-Delgado * and José María Encinar Martín $(1)$ \\ Department of Chemical Engineering and Physical-Chemistry, University of Extremadura, 06006 Badajoz, Spain \\ * Correspondence: senogalesd@unex.es
}

Received: 2 July 2019; Accepted: 29 July 2019; Published: 30 July 2019

check for updates

\begin{abstract}
Universities play an important role in society. On the other hand, more and more governments and international organizations are concerned about the environment. Thus, both in their educational programs and research, as well as in the case of public exhibitions, universities are increasingly including subjects related to the environment and its preservation. In the case of Spain, there are fewer university students than ten years ago (from approximately 140,000 to fewer than 130,000), and the number of students interested in technical and scientific degrees has equally decreased. Consequently, the importance of fostering a scientific culture with concerns in environmental issues is continuously increasing, from schools to universities. The role of real scientific environments, such as laboratories devoted to scientific research, could be an important support for environmental divulgation, as most research carried out at universities have to do with these subjects. The aim of this work was to show a specific case of environmental education in a laboratory devoted to the production of biodiesel and biolubricants, covering a wide range of academic levels and, depending on the audience, selecting the right content (both theoretical and practical). This guide was useful for the laboratory technicians, increasing the interest of the audience (considering the expositions good or excellent, depending on the academic level, and gaining enough or excellent knowledge about biorefineries).
\end{abstract}

Keywords: biodiesel; biolubricants; undergraduate students; high-school students; university students; university graduates

\section{Introduction}

One of the main objectives of universities is the development of society and the solution of its problems. Thus, the production, transmission and dissemination of knowledge are vital. In fact, there are departments of project managers specifically devoted for this purpose [1]. In addition, this task is not exclusively restricted to these kinds of professionals, as many other workers, such as laboratory technicians or researchers at universities, might take part in this knowledge spreading process.

On the other hand, there was a considerable decrease in university students in the last decade in Spain (around 8\%) - in the case of the Extremadura region, this decrease was especially notable (over 20\%), according to data from 2008 to 2018 [2]. As a result, universities are concerned about this fact, taking steps to foster future university enrolment at all academic levels. Consequently, it is common to see many events in universities to attract the attention of primary school and high-school students, especially.

Moreover, environmental awareness is becoming more and more important, with many international organizations taking steps to promote environmental protection from many points of view (such as the Sustainable Development Goals, which are a call for action by all countries and the blueprint to achieve a better and more sustainable future for all [3]). It seems that, one of the main aspects to be taken into account is environmental education, which should be a transversal skill for 
all educational levels [4-6]. Concerning technical and scientific subjects, competency in sustainable development is being incorporated [7]. Moreover, the use of systems thinking applied to education and green chemistry could play an important role in chemistry education [8,9], especially in cases such as the explanation of a biorefinery (to produce biodiesel and biolubricants), as is the case studied in this research work.

The use of biodiesel and biolubricants, compared to their fossil equivalents, could contribute to the sustainable development of many countries and regions, due to their environmentally-friendly nature [10-16]. Thus, the concept of biorefineries, where sustainable raw materials are used and many by-products are re-used, is gaining more importance by researchers [17-19]. However, there are many challenges concerning these products, such as the low oxidative stability compared to fossil materials $[10,15,20-22]$. As a result, further research about overcoming these challenges is required. Indeed, one of the most important research lines of our laboratory, part of the Department of Chemical Engineering and Physical Chemistry, is the improvement of the performance of biodiesel and biolubricants.

In accordance with the above, some practice lessons about biodiesel and biolubricants, which take part in biorefinery processes based on vegetable oils, can be really useful for our university when it comes to technology transfer tasks. In fact, there are regular visits to our facilities (from students to professionals) with this purpose. As other authors have pointed out, the use of laboratories to foster the student's involvement in science subjects might be successful [23].

The aim of this work was to show a specific case of environmental education in a laboratory where biodiesel and biolubricants (part of a biorefinery process) are produced. In this case, the wide range of academic level of the audience, as well as the different kinds of events, is the main challenge to overcome. The practical approach of these exhibitions is suitable to reinforce key concepts such as chemical reaction, density and viscosity, among others (students should be familiar with these terms on account of their academic level). That is the reason why the environmental education in this case was eminently practical.

\section{Materials and Methods}

In order to implement the practical lessons in the laboratory, three aspects were taken into account:

- The characteristics of the audience, speakers and laboratory.

- The theoretical content (to introduce the practical lessons).

- The practical content of these lessons and its assignment according to the kind of audience.

Thus, each aspect is thoroughly explained in the following subsections, with regard to the laboratory of the Department of Chemical Engineering and Physical Chemistry devoted to biodiesel and biolubricant production (biorefinery based on vegetable oils) of the University of Extremadura.

\subsection{Characteristics of the Audience, Speakers and Laboratory}

Due to the interest of the University of Extremadura to engage students and foster a scientific culture (including environmental concern), there are plenty of open-door events, many of them taking place in laboratories in order to show real working conditions or specific subjects. Therefore, laboratory technicians have to face informative talks, practical lessons or exhibitions frequently. In these cases, the function of the laboratory technician (acting as a speaker) depends on the kind of event, with the audience being heterogeneous (especially when it comes to scientific background) and the time available variable. Table 1 shows the main characteristics of the audience depending on their academic level.

Thus, the speaker can face, sometimes in one single day, from primary school pupils to university graduates, which makes the task of teaching difficult, especially taking into account that not all the laboratory technicians have teaching experience. 
Concerning the speakers, they are usually temporary workers, meaning that the staff devoted to exhibitions is continuously changing, making necessary a guide including the theoretical and practical content of these exhibitions.

Table 1. Classification according to the student level.

\begin{tabular}{ccc}
\hline Academic Level & Main Characteristics & Age (Years) \\
\hline Primary school & Pupils with little knowledge on sciences & Below 12 \\
\hline High school & Students with variable knowledge on sciences & $12-18$ \\
\hline University/graduate & $\begin{array}{c}\text { University students and university graduates } \\
\text { (professionals), usually familiar with technical careers }\end{array}$ & Over 18 \\
\hline
\end{tabular}

Regarding the laboratory where these practical lessons take place, it is devoted to biodiesel and biolubricant production and characterization as well as combustion and pyrolysis tests, counting with equipment for this purpose, such as gas chromatographs, reactors, collective protection equipment, etc., apart from the material used in the practical lessons. It has a maximum capacity of 20 people for teaching experiences, not carrying out any dangerous experience during the exhibitions and taking safety precautions by assessing risks and taking preventive measures, as showed by other authors $[24,25]$.

\subsection{Theoretical Content}

Although the lessons are eminently practical, they usually include a brief theoretical introduction, including discussion questions for the audience about their knowledge on biorefineries, biodiesel or biolubricants, among others, in order to increase involvement. The main subjects are shown in Figure 1, and they were classified in blocks. As other authors have pointed out, the teaching experience might be more efficient and the students have increased their ability to make connections between the abstract concepts and concrete examples in the practices [26]. This way, splitting up the theoretical blocks can be useful, especially in this kind of presentation format where not much time is available.

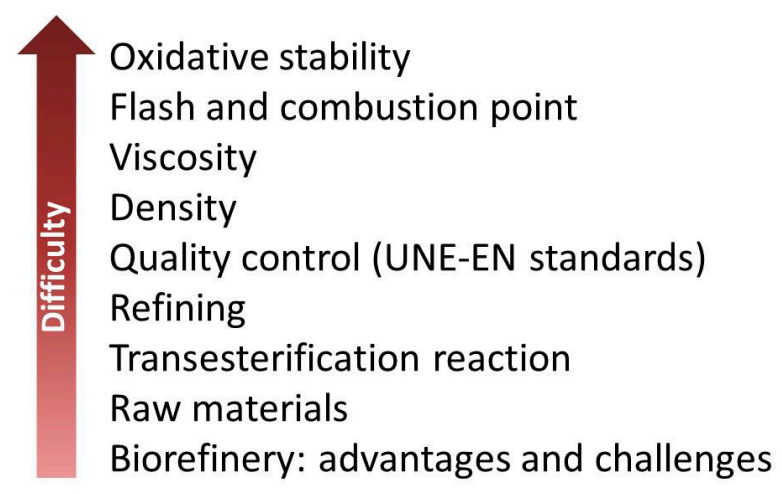

Figure 1. Main theoretical subjects included in the exhibitions about biorefineries.

This way, the main subjects were:

- Biorefinery: that is, using biomass instead of oil (or petroleum) to produce many products such as biofuels. In the case of our study, the biorefinery could be based on vegetable oils, to produce biodiesel and biolubricants, mainly. The main advantages (promoting green chemistry) and challenges (improvement of the yield) were explained.

- Raw materials: Including an explanation about the main feedstocks (from agricultural wastes to fat animals). 
- Transesterification reaction: This is the chemical reaction from which vegetable oils (that is, triglycerides) are converted to biodiesel and biolubricants. The main factors affecting the yield of transesterification were explained.

- Refining: As in a traditional refinery, the products obtained in a biorefinery need refining, that is, purification. During this step, some by-products are separated and might be re-used in other stages.

- Quality control: Mainly according to the UNE-EN 14214, in the case of biodiesel, it has to comply with a lot of standards (paying special attention to density, viscosity or oxidative stability, which will be explained down below, among others).

- Density: Mass divided by volume. It has to comply with a range established in the standard.

- Viscosity: The ease of flowing. It is important for diesel engines, as it will be explained.

- Flash and combustion points: It is a good indicator of safety during storage. It is the temperature at which biodiesel starts burning inconsistently or permanently.

- Oxidative stability: It is the time that biodiesel takes to oxidize. It is obtained by bubbling air into a sample at high temperature and dissolving the by-products of oxidation in water (and measuring its conductivity).

As can be seen in Figure 1, the concepts included in these theoretical introductions were classified according to their intrinsic difficulty. Thus, for an 8-year-old pupil, the oxidative stability of biodiesel (or biolubricants) would not be included in the speech. Nevertheless, there are some subjects, especially in the "easy" area, that could be addressed in different ways. For instance, the advantages and disadvantages of biorefineries could include the easiest contents (zero-net $\mathrm{CO}_{2}$ emissions, cleaner products, etc.) or the most complex ones (the right selection of raw materials to avoid competition with edible crops, for instance). The same could be said about the definition of a biorefinery in Figure 2, where plenty of concepts are covered, thoroughly examining methanol re-use or glycerol use depending on the academic level of the audience.

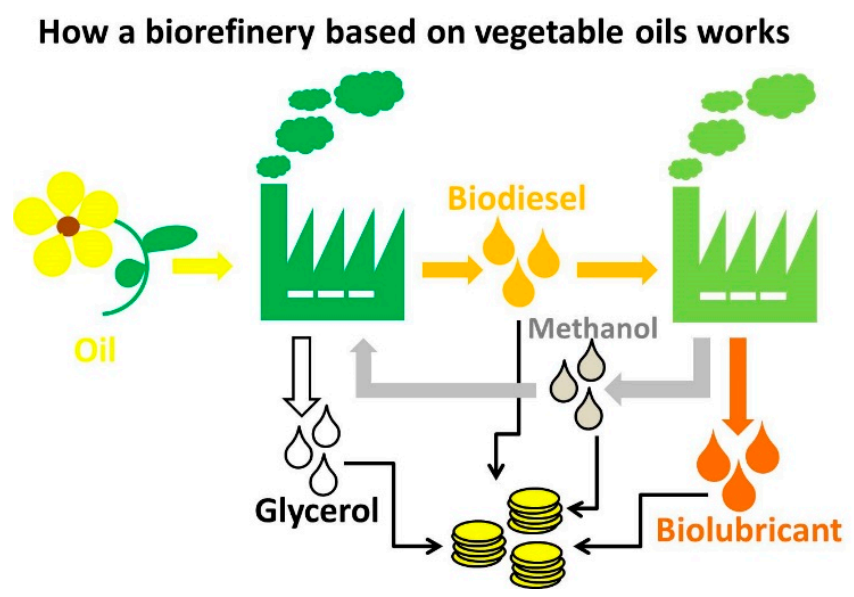

Figure 2. Functioning scheme of a biorefinery based on vegetable oil (biodiesel and biolubricant production).

This way, and depending on the kind of audience (which could reduce the most difficult concepts, such as oxidative stability or flash and combustion points) and time available, the selection of theoretical concepts will change, according to the criterion of the laboratory technician.

\subsection{Practical Content}

As the old adage goes, "a gram of action is worth tons of theory". In the case of this study, it is absolutely applicable, as the most important part of the speech is the practical content. The combination of theoretical and practical subjects could enhance students' learning and interest [27]. Thus, after the right selection of theoretical subjects included in the previous section, the most suitable practical contents depending on the academic level are shown in Table 2. 
Table 2. Practical content assignment according to academic level.

\begin{tabular}{llc}
\hline Academic Level ${ }^{\mathbf{1}}$ & Practice & Time (min) \\
\hline All levels & $\begin{array}{l}\text { Biodiesel and biolubricant showcase } \\
\text { Biodiesel and biolubricant production (chemical reaction) }\end{array}$ & $5-10$ \\
\hline Primary school & Liquid race & 5 \\
\hline High school/university & $\begin{array}{l}\text { Density determination } \\
\text { Viscosity performance } \\
\text { Flash and combustion points }\end{array}$ & $5-10$ \\
\hline University/graduate & Oxidative stability & 10 \\
\hline \multicolumn{2}{c}{ Depending on the time available, some practices could include concepts related to lower levels. }
\end{tabular}

As can be observed, each speech usually includes two or three practices, with a maximum time limit of $30 \mathrm{~min}$ (which can vary depending on the format of the exhibition required by the University). The teaching sequence was as follows: 1st theoretical content, 1st practical content, 2nd theoretical content, 2nd practical content, etc. Thus, imparting all the theoretical blocks at once was avoided, in order to increase the interest of the audience (especially in the case of primary and high-school students).

For the development of each practice, the supervision of professors was necessary. Student involvement in the practical content depended on the risk related to each practice, with the laboratory technician performing the most dangerous activities (for instance involving high temperatures), if necessary. Otherwise, involvement was necessary, asking the audience to take part in the practice, taking all measures to ensure safety during this experience.

Moreover, it was proved that the quality of learning relies on the learning activities and students' involvement in exploratory action [28]. Especially at the beginning of a practice, the students are asked to carry out each task as freely as possible, in order to increase the engagement of the student to the practice and, therefore, to improve the learning process [29]. If the student is not carrying out the task properly, then the intervention of the laboratory technician was required, by suggesting or performing the practice, always following the safety standards.

Finally, a short questionnaire about the exposition was delivered to the audience, when possible. Thus, a short knowledge test (with 5 questions, with 3 options each), adapted to the academic level, as well as a satisfaction survey (with 4 questions, with 5 options each) was included in this short questionnaire. According to the knowledge test, the results about the knowledge of the audience went from "not enough" to "excellent" and for the satisfaction survey, the results about the exposition went from "poor" to "excellent". For further information, we included Supplementary Material with the templates, answers and ranges of the questionnaires.

\section{Results and Discussion}

The explanation of each practice is covered in the following sub-sections, containing the main steps to carry out the experience.

\subsection{Biodiesel and Biolubricant Showcase}

After a brief debate (asking to the audience about possible raw materials for biodiesel and biolubricant production) and an explanation about refineries based on vegetable oils (see Figure 2), several samples (including vegetable oils, biodiesel and reagents and products obtained during transesterification) are shown, as can be seen in Figure 3, with the aim of making the raw materials and the main by-products of a typical biorefinery process familiar for the audience. Thus, the main conclusions for the audience, after a short discussion about the main raw materials for biorefineries, were the following:

- A biorefinery might be based on a wide range of raw materials, from different sources (vegetable and animal) and with different characteristics (viscosity, dirtiness, etc.). 
- The main objective of transesterification is to "unify" viscosity. Thus, the example of the animal fat (Figure 3a right) is self-explicative: after the chemical reaction, a biodiesel with a suitable viscosity for diesel motors is obtained from a semi-solid waste which would be impossible to introduce in a diesel engine.

- The example of the used oil was especially familiar for the students, being a representative example of a waste difficult to manage which might be used as an energy source or for biolubricant production.

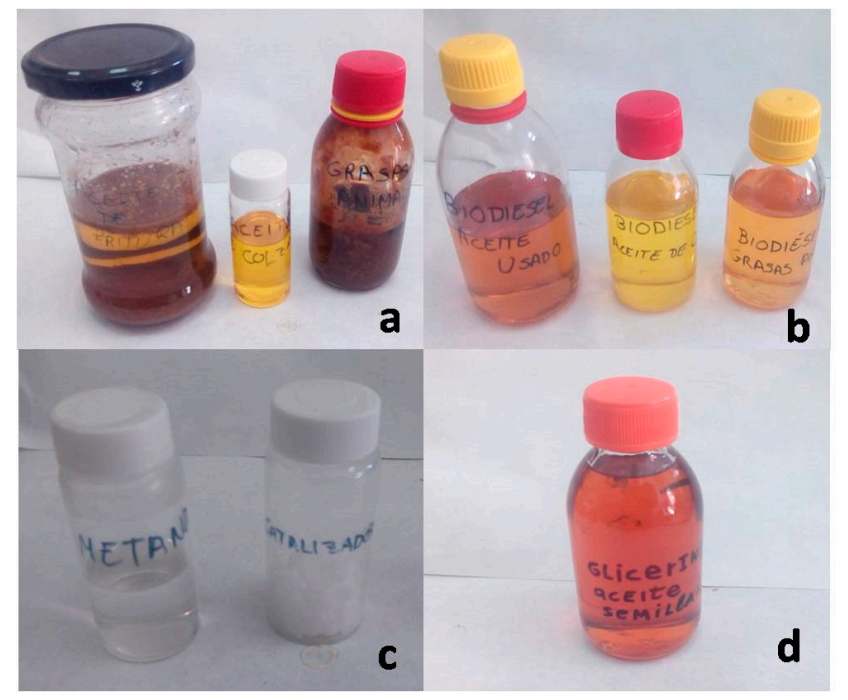

Figure 3. Sample showcase, with: (a) raw materials (fried oil, rapeseed oil and animal fats); (b) biodiesel obtained from fried oil, rapeseed oil and animal fats; (c) reagents (methanol and catalyst); (d) by-product (glycerol).

This way, it was highly recommended to recycle fried and used oils. Otherwise, as is shown in a water sample in Figure 4, its pollutant effect on water is clear. Fortunately, when asked about this issue, $95 \%$ of the audience confirmed that they recycle this used oil in clean points.

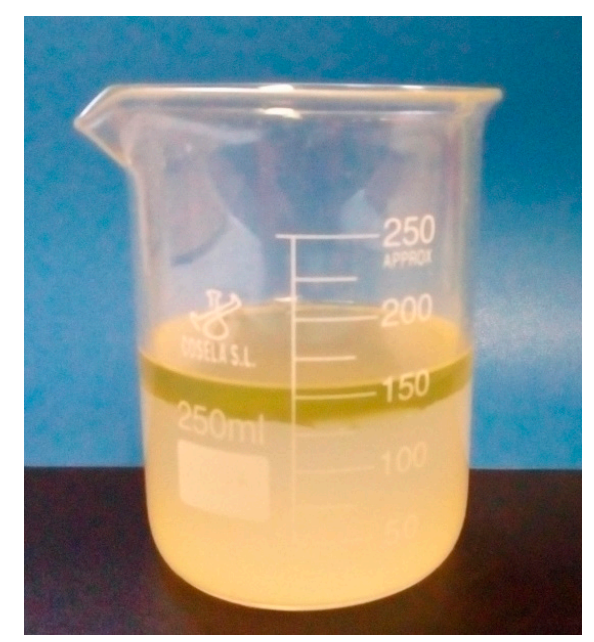

Figure 4. Effect of the addition of $5 \mathrm{~mL}$ of fried oil in $100 \mathrm{~mL}$ of water.

Consequently, by using such a familiar waste for the audience, they found the presentation of biorefineries more interesting, frequently asking about the transesterification process, which is explained in the following section. As other authors concluded, the use of proposals to improve the scientific competences of the students usually derived in more interest, as happened in this case-study [29]. 


\subsection{Biodiesel and Biolubricant Production (Chemical Reaction)}

Depending on the time available and, especially, on the academic level, the transesterification of biodiesel and biolubricants was explained differently. Thus, from our experience, for primary school students, the "comparison" between a chemical reaction like transesterification and a cooking recipe was really appreciated (especially when this comparison was made with a typical dish that everybody knows in our country, such as the Spanish omelette). The similarities established between reagents and ingredients and between products and the final dish were suitable for this explanation at this academic level. See Figure 5

\section{Chemical reactions are, somehow, like a recipe}

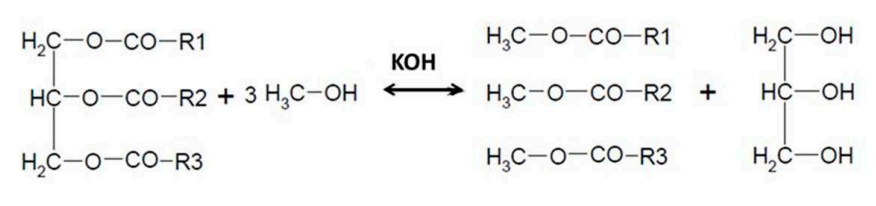

\section{Triglyceride Methanol Biodiesel Glycerol}

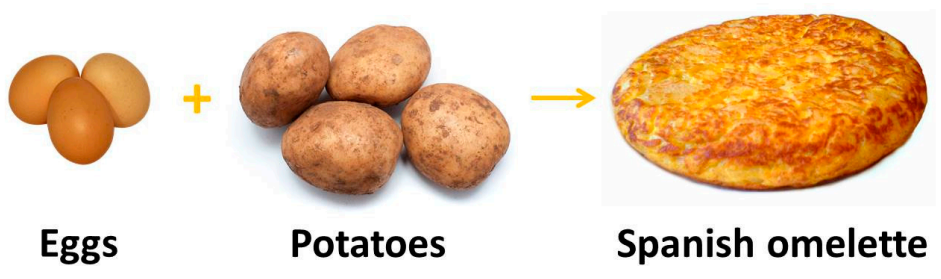

Figure 5. Explanation of biodiesel production (for primary school pupils).

For higher academic levels, such as high-school, university students and university graduates, a small-scale reactor where the transesterification reaction takes place (by using vegetable oil, methanol and $\mathrm{NaOH}$ as a catalyst, stirring at $700 \mathrm{rpm}$ and heating at $60^{\circ} \mathrm{C}$, as explained elsewhere [30], in Figure 6), as well as the explanation of the main factors to be taken into account to increase the yield (that is, temperature, reagent proportion and catalyst, Figure 7), were used.

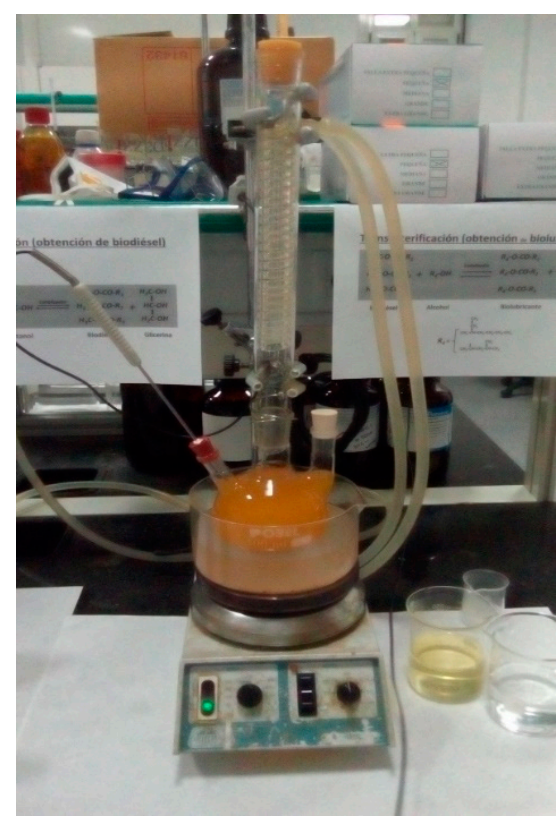

Figure 6. Small-scale reactor for transesterification (for high-school students). 


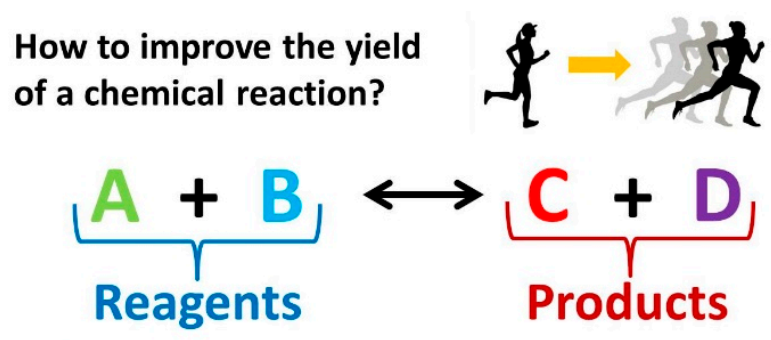

Temperature increase

Use of catalysts

Excess reagent

Figure 7. Different factors affecting the yield of a chemical reaction (for high-school students).

During the discussion about the improvement of the yield of a chemical reaction (which is one of the main subjects in chemical courses at these academic levels), a basic explanation about the influence of temperature increase (which improve the yield of the reaction as long as it is endothermic), the use of catalysts (which reduces the activation energy of the chemical reaction, requiring less temperature among others) and the excess reagent (which changes the balance to produce more products) took place. Moreover, if the academic level of the student is high enough, the term sustainability is introduced, to point out that we must consider whether high temperatures or catalyst concentrations are worth it to increase slightly the yield of a reaction, for instance.

Thus, the student could conclude that the optimization of these chemical reactions taking place in a biorefinery, apart from the re-use of different by-products (as explained in Figure 2), is essential to make this process competitive compared to other highly polluting ones.

In fact, terms such as temperature control, catalyst and excess reagent are reviewed in this practice, exploiting the showcase in Figure 3 to visualize the chemical reaction for further clarification.

\subsection{Density Determination}

Before the explanation of the following practices, for high academic levels, the reference of the UNE-EN 14,214 standard was mentioned [31], as it is vital to compare the biodiesel obtained (as explained in the previous section) with standards which guarantee that the use of biodiesel in diesel engines is safe and suitable. Thus, parameters such as density, viscosity, flash and combustion point or oxidative stability are important to assess the suitability of this fuel for engine performance and storage.

For the density determination for biodiesel, a densimeter was used. In this case, the student is asked to carry out three tasks:

- Firstly, to interpret the scale of the densimeter.

- Second, to measure the density in a real sample of biodiesel, as shown in Figure 8.

- Finally, to assess whether this biodiesel is suitable, according to the EN 14214 standard.

This same procedure was established by the rest of the parameters; that is, the standard was always taken into account, apart from the corresponding explanation. 


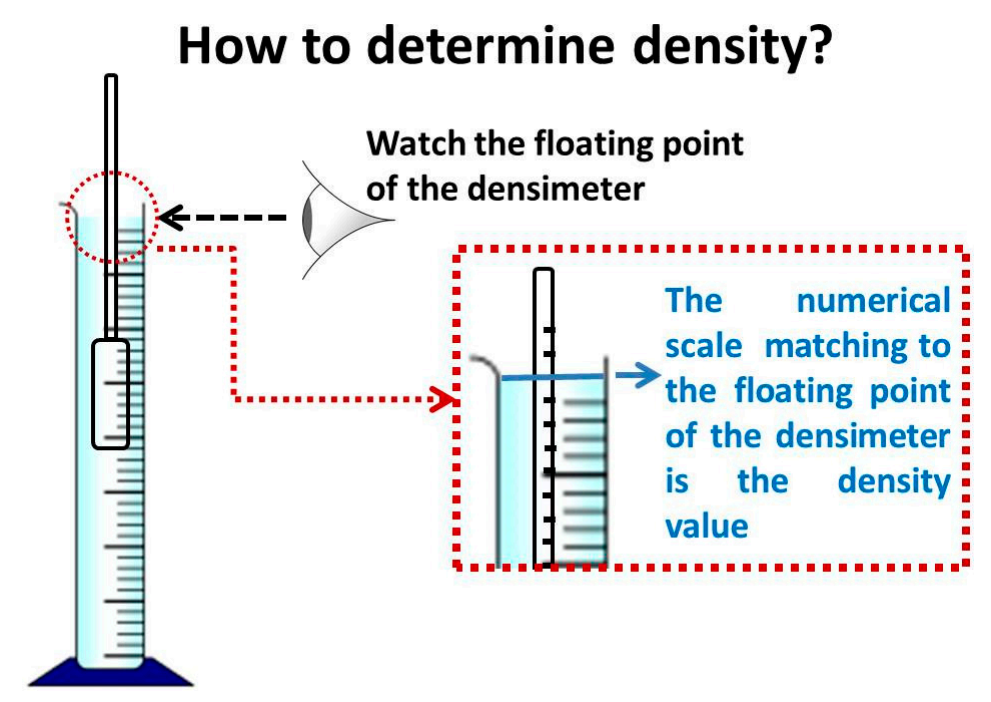

Figure 8. Density determination (high-school/university students).

\subsection{Viscosity (Liquid Race and Viscosity Performance)}

For viscosity determination, an initial discussion about the definition of viscosity and examples of substances with different viscosities was suggested. As expected, the main substances suggested by the students were (in order of increasing viscosity): water, milk and honey. Based on these, the explanation of the following practices was much easier and understandable.

In this case, regarding high-school students, the use of a viscosimeter was used, but not to measure a real value of viscosity, but to carry out a "liquid race" with two liquids (biodiesel and oil, which is more viscous). Then, a student is asked to time this "liquid race", taking into account the start and finish points, as explained in Figure 9.

\section{Biodiesel race: which liquid will win?}
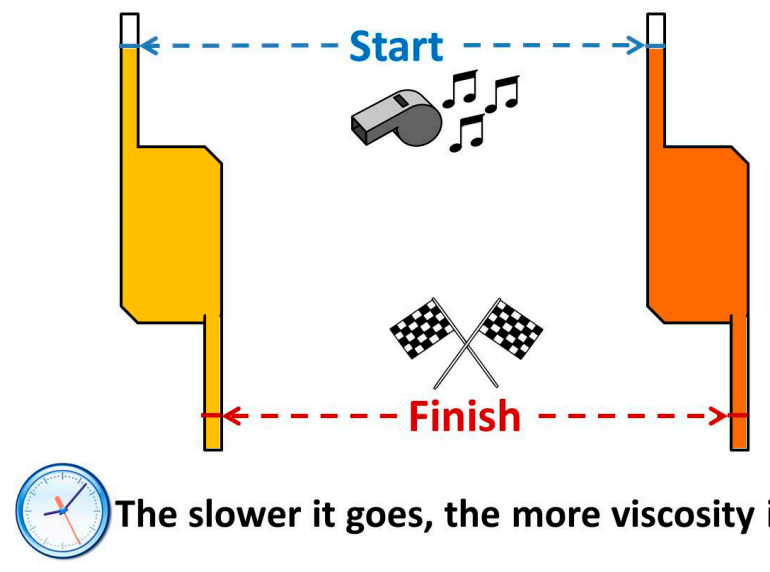

\section{The slower it goes, the more viscosity it has}

Figure 9. Qualitative determination of biodiesel viscosity by comparing two samples (for high-school students).

For university students, a real-case viscosity measure is carried out, with temperature control (which is really important, as viscosity decreases with temperature, as can be seen, for instance, in honey) and the use of an equation depending on the kind of viscosimeter used, expressing the value in centistokes (cSt), and comparing with the standard Equation (1). Similar determinations with different samples were carried out by other authors [32].

$$
v=\mathrm{K} \cdot \mathrm{t}
$$


where $v$ is viscosity (expressed in cSt or $\mathrm{mm}^{2} \cdot \mathrm{s}^{-1}$ ), $\mathrm{K}$ is the constant of the viscosimeter (expressed in $\left.\left(\mathrm{mm}^{2} \cdot \mathrm{s}^{-1}\right) \cdot \mathrm{s}^{-1}\right)$ and $\mathrm{t}$ is the time that the liquid takes to flow in the viscosimeter (expressed in $\mathrm{s}$ ).

Moreover, the importance of complying with the EN-14214 standard is explained by the following practice, in Figure 10, where two sprayers were used (containing biodiesel and oil, as in Figure 9). After asking a student to use both sprayers, the difference between the performances of both liquids was compared to the behaviour in a real engine. Consequently, the bad performance of the oil (Figure 10, right), generating small leaks, was similar to the possible obstruction or deposit generation during the injection in engines.

\section{Importance of viscosity: Difference between good and bad injection performance}
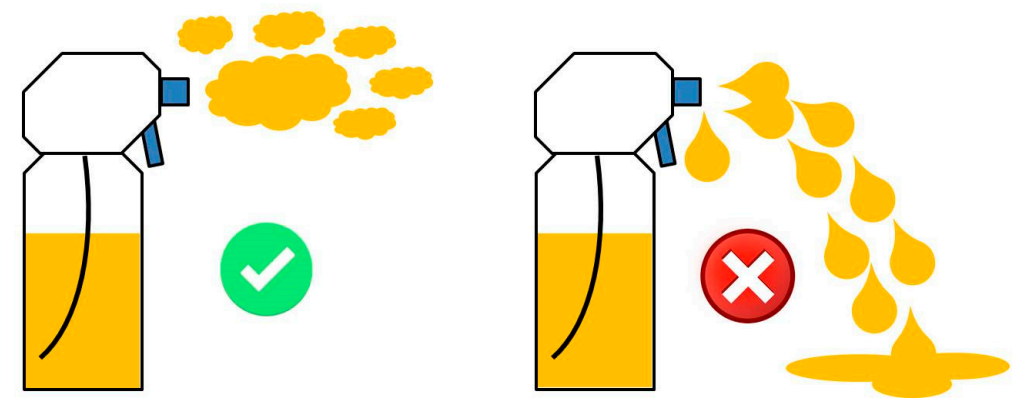

Figure 10. Comparison of the performance of biodiesel with different viscosity values (high-school and university students).

As a result, the student could realize the importance of complying with the standard. Otherwise, there would be real problems with the commercialization of biodiesel and, consequently, its competition with diesel would be weak, not contributing to environmental sustainability.

\subsection{Flash and Combustion Points}

Concerning flash and combustion points, which are very important parameters to assess the safety of biodiesel and biolubricants during storage, a brief explanation of this concept was carried out (temperature at which a spark or a constant flame is produced when a substance is increasingly heated). A visual explanation of this practice is shown in Figure 11, according to the Cleveland open cup method [33].

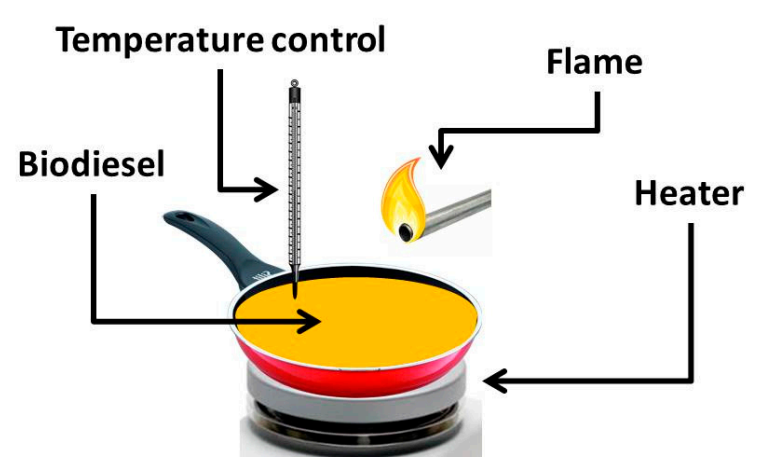

Figure 11. Functioning scheme of flash and combustion point determination (university students).

As the practice about the determination of these points requires the use of high temperatures and a flame, for safety reasons, this experience is carried out without the flame and explaining the expected result. Only under rare circumstances, and with the observance of all the safety measurements, this 
practice was carried out in these kinds of exhibitions, with the laboratory technician carrying out the whole experience.

\subsection{Oxidative Stability}

Oxidative stability, which is a complex phenomenon, is suitable for advanced academic levels. After explaining the main disadvantage of biodiesel (that is, its low oxidative stability), and as can be seen in Figure 12, the determination of this parameter is explained by using the Rancimat method [34].

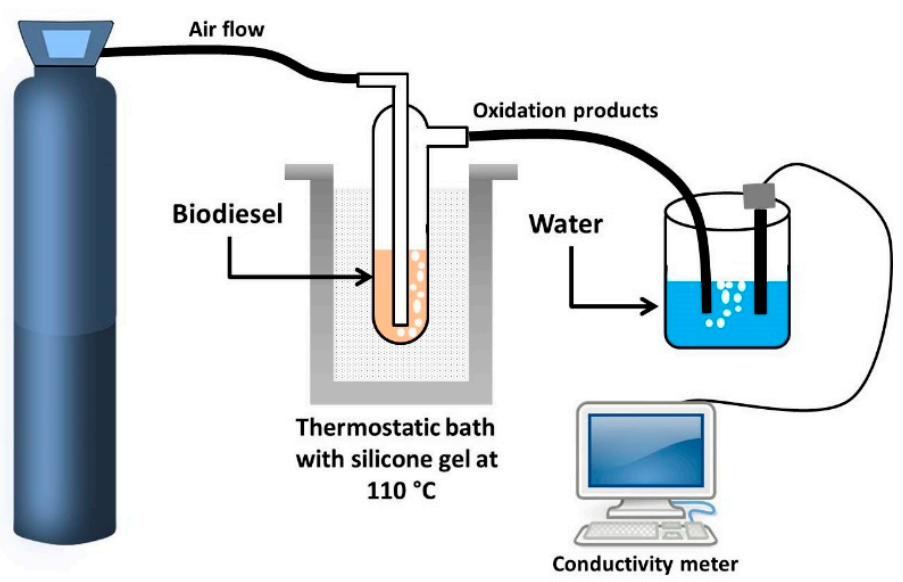

Figure 12. Functioning scheme of the Rancimat method (university students).

One of the main interesting characteristics of this practice is the understanding of the whole process, where biodiesel (or biolubricant) is oxidized by using a considerable air flow and high temperatures, accelerating the self-oxidation produced naturally when biodiesel is stored. The increase in the conductivity of water, where the by-products of auto-oxidation are dissolved, shows a characteristic behaviour shown in Figure 13. Thus, if we pay attention to one of these lines, a stationary stage is observed (where conductivity did not increase over time). Afterwards, and abruptly, a sharp increase in conductivity was observed, when the auto-oxidation is more remarkable. The time when this increase takes place is the induction point, which assesses the oxidative stability of biodiesel. Thus, the longer this point takes place, the more stable the sample is. For instance, in Figure 13, the sample represented by the black line is the least stable.

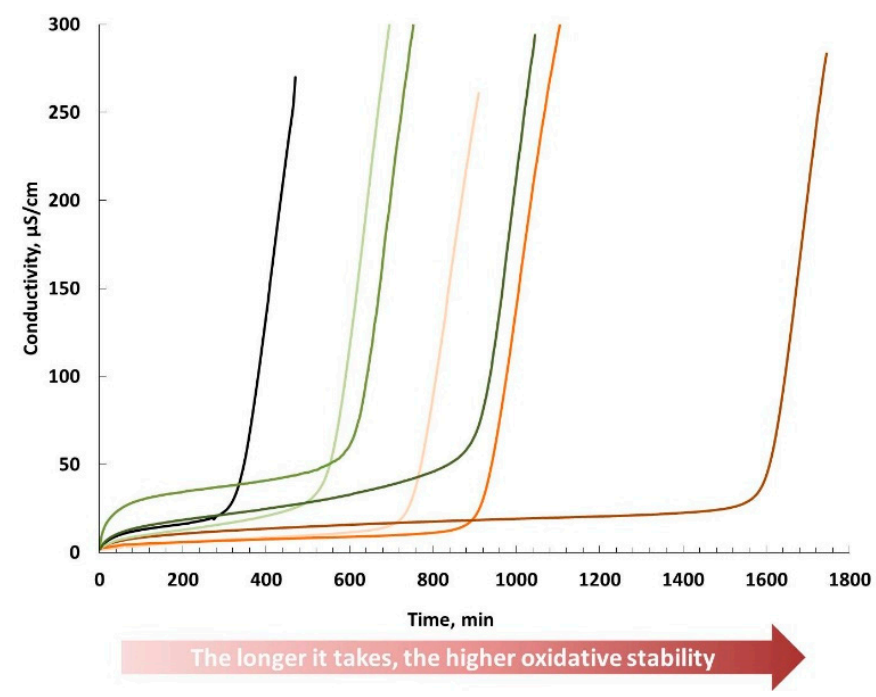

Figure 13. Comparison of different samples and their oxidative stability (university students). 
To conclude this experience, a student is asked to measure the induction point according to a plot (as this determination takes hours, only the experimental design and a graph are shown to the audience), as can be seen in Figure 14 .

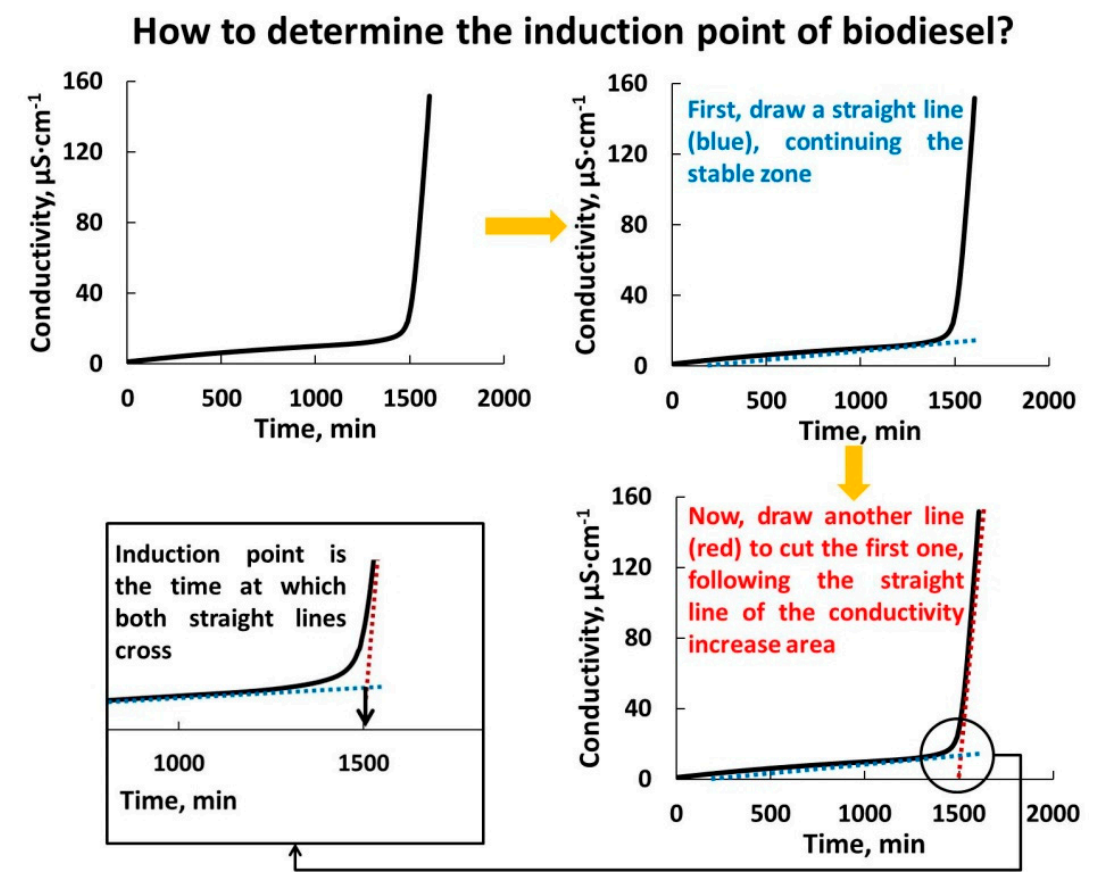

Figure 14. Steps for induction point determination (university students).

Finally, a short debate about the advantage of biodegradability versus short storage stability was suggested, including the need of adding antioxidants (sometimes no-natural ones, which could contradict the environment friendly nature of biodiesel). This way, the audience realized that the use of renewable energies might, sometimes, be complex.

To sum up, and according to the knowledge tests and satisfaction survey carried out after the presentation (when possible), the audience gained enough knowledge about biorefineries, obtaining good results in the tests and showing a good acceptation of the presentations, as shown in Table 3:

Table 3. Average results of the knowledge tests and satisfaction surveys.

\begin{tabular}{ccc}
\hline Academic Level & Knowledge Test $^{\mathbf{1}}$ & Satisfaction Survey $^{\mathbf{1}}$ \\
\hline Primary school & 3.5 & 16.1 \\
High school/university & 4.2 & 15.7 \\
University/graduate & 4.7 & 18.0 \\
\hline
\end{tabular}

${ }^{1}$ The complete knowledge test and satisfaction survey are included as Supplementary Materials.

Thus, the results were acceptable, as the knowledge tests were, in general, enough or excellent, whereas the exposition was greatly appreciated-between good and excellent, depending on the academic level. When these kinds of tests were not possible to be carried out, at least a short debate was started, to check the knowledge of the audience, asking directly about the satisfaction of the speech.

\section{Conclusions}

A case study on environmental education for students at different educational backgrounds, by explaining a biorefinery based on vegetable oils, was presented. The main challenges faced were the following: 
- Heterogeneous educational background of the audience. Although the organizers try to group the audience to make the audience as homogeneous as possible, it is always heterogeneous, adapting the content of the speech to the lowest level in these cases. Moreover, there are differences in level between different groups.

- Different speakers, depending on the availability. Mainly due to job instability, trying to solve this problem by training the new workers and inviting them to assist in real expositions.

- Lack of teaching experience, in general. Although many professionals do not have any teaching experience, they receive some courses about didactics.

- Decreasing enrolment of students. This is the main reason why there are so many events to attract students, varying depending on time and academic level.

To solve these problems, the implementation of a small didactic unit was necessary, following these steps:

- Classification according to educational background.

- $\quad$ Ranking of the contents (especially the practical lessons) according to their difficulty.

- Content assignment depending on the audience.

As a result, a set of practical lessons were presented, covering the main concepts about biorefineries (biodiesel and biolubricant) in different blocks which were interrelated.

The main advantages found, after three years of implementation, were:

- $\quad$ Easier and better adaptation to the audience.

- Better performance in the laboratory (as the time to rehearse was reduced).

- Increased interest and satisfaction of the audience, regardless of the educational level, promoting environmental awareness easily.

- Useful practical content, for its use in high-school and universities (to review concepts such as chemical reaction, catalyst, density or viscosity), was presented.

From the point of view of the audience, the following could be concluded:

- The environment protection is promoted by the use of biorefineries, where sustainable raw materials are used and almost every by-product can be re-used.

- The energy use of a waste like fried oils was proved, implying a double advantage: waste management and energy production.

- The optimization of chemical reactions is important, to improve the yield in a sustainable way.

- The quality of biodiesel was checked, being environmentally friendly and similar to diesel.

Supplementary Materials: The following are available online at http://www.mdpi.com/2227-7102/9/3/202/s1.

Author Contributions: Conceptualization, S.N. and J.M.E.; methodology, S.N. and J.M.E.; resources, J.M.E.; investigation, S.N. and J.M.E.; data curation, S.N.; Writing-Original Draft preparation, S.N.; Writing-Review And Editing, S.N. and J.M.E.; visualization, S.N. and J.M.E.; supervision, S.N. and J.M.E.; project administration, J.M.E.; funding acquisition, J.M.E.

Funding: This research was funded by Junta de Extremadura and FEDER funds, grant numbers GR 18150 and IB 18028.

Acknowledgments: The authors are grateful to the Junta de Extremadura and FEDER (Fondo Europeo de Desarrollo Regional "Una manera de hacer Europa”), for finantial help by projects GR18150 and IB18028, repectively. Also, we would like to acknowledge the "help and guidance" of the pupils, students and professionals that have visited our facilities for three years, as they were our "real teachers" by helping us to improve every day. Special mention for Isabel Vargas González, who helped us to improve this article.

Conflicts of Interest: The authors declare no conflict of interest. 


\section{References}

1. Cerezo-Narváez, A.; de los Ríos Carmenado, I.; Pastor-Fernández, A.; Yagüe Blanco, J.; Otero-Mateo, M. Project Management Competences by Teaching and Research Staff for the Sustained Success of Engineering Education. Educ. Sci. 2019, 9, 44. [CrossRef]

2. Ministerio de Educación, C. y D. Estadísticas Universidad. Available online: https://www.educacionyfp.gob. es/servicios-al-ciudadano-mecd/estadisticas/educacion/universitaria/estadisticas/alumnado/2017-2018_ Av/Grado-y-Ciclo.html (accessed on 2 May 2019).

3. Nations, U. Sustainable Development Goals. In Proceedings of the High-level Political Forum (HLPF) under the 74th Session of the General Assembly, New York, NY, USA, 24-25 September 2019.

4. Zamora-Polo, F.; Sánchez-Martín, J.; Corrales-Serrano, M.; Espejo-Antúnez, L. What do university students know about sustainable development goals? A realistic approach to the reception of this UN program amongst the youth population. Sustainability 2019, 11, 3533. [CrossRef]

5. Uitto, A.; Saloranta, S. Subject teachers as educators for sustainability: A survey study. Educ. Sci. 2017, 7, 8. [CrossRef]

6. Notari Llorens, M.; Pardo Fabregat, F.; Martinez-Poveda, A.; Jordan Vidal, M. Learning ecological concepts in secondary schools of the northeast of Spain. Educ. Sci. 2019, 9, 53. [CrossRef]

7. Sanganyado, E.; Nkomo, S. Incorporating sustainability into engineering and chemical education using E-Learning. Educ. Sci. 2018, 8, 39. [CrossRef]

8. Orgill, M.; York, S.; MacKellar, J. Introduction to systems thinking for the chemistry education community. J. Chem. Educ. 2019. [CrossRef]

9. York, S.; Lavi, R.; Dori, Y.J.; Orgill, M. Applications of systems thinking in stem education. J. Chem. Educ. 2019. [CrossRef]

10. Rodionova, M.V.; Poudyal, R.S.; Tiwari, I.; Voloshin, R.A.; Zharmukhamedov, S.K.; Nam, H.G.; Zayadan, B.K.; Bruce, B.D.; Hou, H.J.M.; Allakhverdiev, S.I. Biofuel production: Challenges and opportunities. Int. J. Hydrog. Energy 2017, 42, 8450-8461. [CrossRef]

11. Othman, M.F.; Adam, A.; Najafi, G.; Mamat, R. Green fuel as alternative fuel for diesel engine: A review. Renew. Sustain. Energy Rev. 2017, 80, 694-709. [CrossRef]

12. Kania, D.; Yunus, R.; Omar, R.; Abdul Rashid, S.; Mohamad Jan, B. A review of biolubricants in drilling fluids: Recent research, performance, and applications. J. Pet. Sci. Eng. 2015, 135, 177-184. [CrossRef]

13. Salimon, J.; Salih, N.; Yousif, E. Biolubricants: Raw materials, chemical modifications and environmental benefits. Eur. J. Lipid Sci. Technol. 2010, 112, 519-530. [CrossRef]

14. Huang, D.; Zhou, H.; Lin, L. Biodiesel: An alternative to conventional fuel. Energy Procedia 2011, 16, 1874-1885. [CrossRef]

15. Aransiola, E.F.; Ojumu, T.V.; Oyekola, O.O.; Madzimbamuto, T.F.; Ikhu-Omoregbe, D.I.O. A review of current technology for biodiesel production: State of the art. Biomass Bioenerg. 2014, 61, 276-297. [CrossRef]

16. De Man, R.; German, L. Certifying the sustainability of biofuels: Promise and reality. Energy Policy 2017, 109, 871-883. [CrossRef]

17. Palmeros Parada, M.; Osseweijer, P.; Posada Duque, J.A. Sustainable biorefineries, an analysis of practices for incorporating sustainability in biorefinery design. Ind. Crop. Prod. 2017, 106, 105-123. [CrossRef]

18. Moncada, B.J.; Aristizábal, M.V.; Cardona, A.C.A. Design strategies for sustainable biorefineries. Biochem. Eng. J. 2016, 116, 122-134. [CrossRef]

19. Zhang, Y.H.P. Next generation biorefineries will solve the food, biofuels, and environmental trilemma in the energy-food-water nexus. Energy Sci. Eng. 2013, 1, 27-41. [CrossRef]

20. Doria Serrano, M.D.C. Química verde: Un nuevo enfoque para el cuidado del medio ambiente. Educ. Química 2018, 20, 412-420. [CrossRef]

21. Knothe, G.; Razon, L.F. Biodiesel fuels. Prog. Energy Combust. Sci. 2017, 58, 36-59. [CrossRef]

22. Dunn, R.O. Antioxidants for improving storage stability of biodiesel. Biofuels Bioprod. Biorefin. 2008, 2, 304-318. [CrossRef]

23. Affeldt, F.; Weitz, K.; Siol, A.; Markic, S.; Eilks, I. A Non-Formal Student Laboratory as a Place for Innovation in Education for Sustainability for All Students. Educ. Sci. 2015, 5, 238-254. [CrossRef]

24. Goldstein, S.W. Biodiesel from Seeds: An Experiment for Organic Chemistry. J. Chem. Educ. 2014, 91, 1693-1696. [CrossRef] 
25. De La Rosa, P.; Azurin, K.A.; Page, M.F.Z. Soybean Oil: Powering a High School Investigation of Biodiesel. J. Chem. Educ. 2014, 91, 1689-1692. [CrossRef]

26. Craven, S. Teaching Chemistry in the Block Schedule. J. Chem. Educ. 2009, 78, 488. [CrossRef]

27. Lanning, S.; Brown, M. Education Sciences Undergraduate Research as a High Impact Practice in Higher Education; Association of American Colleges and Universities: Washington, DC, USA, 2019; pp. 9-10.

28. Muhonen, H.; Pakarinen, E.; Poikkeus, A.M.; Lerkkanen, M.K.; Rasku-Puttonen, H. Quality of educational dialogue and association with students' academic performance. Learn. Instr. 2018, 55, 67-79. [CrossRef]

29. Viera, L.I.; Ramírez, S.S.; Fleisner, A. El laboratorio en Química Orgánica: Una propuesta para la promoción de competencias científico-tecnológicas. Educ. Quim. 2017, 28, 262-268. [CrossRef]

30. Martínez, G.; Sánchez, N.; Encinar, J.M.; González, J.F. Fuel properties of biodiesel from vegetable oils and oil mixtures. Influence of methyl esters distribution. Biomass Bioenerg. 2014, 63, 22-32. [CrossRef]

31. UNE-EN 14214: 2013 V2+A1: 2018. Liquid Petroleum Products_Fatty Acid Methyl Esters (FAME) for Use in Diesel Engines and Heating Applications—Requirements and Test Methods; Asociacion Espanola de Normalizacion: Madrid, Spain, 2018.

32. Garrett, B.; Matharu, A.S.; Hurst, G.A. Using Greener Gels to Explore Rheology. J. Chem. Educ. 2017, 94, 500-504. [CrossRef]

33. UNE-EN 51023: 1990. Petroleum Products. Determination of Flash and Fire Points. Cleveland Open Cup Method; Asociacion Espanola de Normalizacion: Madrid, Spain, 1990.

34. Focke, W.W.; Westhuizen, I.; Van Der Oosthuysen, X. Biodiesel oxidative stability from Rancimat data. Thermochim. Acta 2016, 633, 116-121. [CrossRef]

(C) 2019 by the authors. Licensee MDPI, Basel, Switzerland. This article is an open access article distributed under the terms and conditions of the Creative Commons Attribution (CC BY) license (http://creativecommons.org/licenses/by/4.0/). 